\title{
INCLUSÃO, INTERCULTURALIDADE E INOVAÇÃO PEDAGÓGICA NO CONTEXTO DO ENSINO SUPERIOR: O QUE DIZEM OS GESTORES
}

\author{
INCLUSIÓN, INTERCULTURALIDAD E INNOVACIÓN PEDAGÓGICA \\ EN EL CONTEXTO DE LA ENSEÑANZA SUPERIOR: LO QUE DICEN LOS \\ GESTORES
}

\author{
INCLUSION, INTERCULTURALITY AND PEDAGOGICAL INNOVATION IN \\ THE CONTEXT OF HIGHER EDUCATION: WHAT MANAGERS SAY
}

\author{
Marco Antonio Melo FRANCO ${ }^{1}$ \\ Marcilene Magalhães da SILVA ${ }^{2}$ \\ Edmilson Minoru TORISU ${ }^{3}$
}

RESUMO: O debate acadêmico sobre os temas da Inclusão, da Interculturalidade e da Inovação Pedagógica tem ganhado notoriedade no cenário internacional. No intuito de investigar como os gestores de universidades têm compreendido estes conceitos e, de alguma forma, os colocado em execução em suas instituições é que aqui apresentamos uma pesquisa cuja a abordagem é qualitativa em formato de um estudo de caso sobre a Universidade Federal de Ouro Preto/UFOP, no estado de Minas Gerais, Brasil. Os dados foram coletados a partir da aplicação de um questionário com questões abertas sobre os três conceitos e a sua articulação com a prática. A partir de um recorte na pesquisa, os resultados evidenciam que os gestores possuem um maior conhecimento sobre o tema da Inclusão, o que não se estende aos outros dois conceitos. Identificam algumas ações da universidade também mais centradas no campo da inclusão, particularmente, da pessoa com deficiência.

PALAVRAS-CHAVE: Ensino superior. Inclusão. Interculturalidade. Inovação pedagógica.

RESUMEN: Los estudios sobre los temas de la Inclusión, de la Interculturalidad y de la Innovación Pedagógica ha ganado notoriedad en el escenario internacional. En este artículo proponemos investigar cómo los gestores de universidades han comprendido conceptualmente estos temas y como perciben la materialización de esos conceptos en sus instituciones. De esta forma, presentamos una investigación cuyo enfoque es cualitativo en formato de un estudio de caso sobre la Universidad Federal de Ouro

\footnotetext{
${ }^{1}$ Universidade Federal de Ouro Preto (UFOP), Ouro Preto - MG - Brasil. Docente do Departamento de Educação e do Programa de Pós-graduação em Educação. Doutorado em Ciências da Saúde, com ênfase em Saúde da criança e do adolescente (Faculdade de Medicina / UFMG-2009). ORCID: https://orcid.org/0000-0002-0159-4109. E-mail: mamf.franco@gmail.com

${ }^{2}$ Universidade Federal de Ouro Preto (UFOP), Ouro Preto - MG - Brasil. Mestre em Educação. ORCID: https://orcid.org/0000-0001-7304-6817. E-mail: marcilenemag@ gmail.com

${ }^{3}$ Universidade Federal de Ouro Preto (UFOP), Ouro Preto - MG - Brasil. Docente do Departamento de Educação Matemática. Doutorado em Educação pela Universidade Federal de Minas Gerais com período sanduíche na Rutgers - University of the State of New Jersey - USA. ORCID: http://orcid.org/0000-00031496-3695. E-mail: etorisu@gmail.com
} 
Preto-UFOP, en el Estado de Minas Gerais, Brasil. Los datos fueron recolectados a partir de la aplicación de un cuestionario con preguntas abiertas sobre los tres conceptos y su articulación con la práctica. Los resultados demuestran que los gestores poseen un mayor conocimiento sobre el tema de la Inclusión, lo que no se percibe en relación a los otros dos conceptos. Acerca de las acciones de inclusión, interculturalidad e innovación pedagógica, realizadas en la universidad, los gestores las perciben como acciones de inclusión de las personas con discapacidad.

PALABRAS CLAVE: Enseñanza superior. Inclusión. Interculturalidad. Innovación pedagógica.

ABSTRACT: The academic debate on the themes of Inclusion, Interculturality and Pedagogical Innovation has gained notoriety in the international scene. With the objective of investigating how university managers have understood these concepts and, somehow, put these concepts in execution in their institutions is that here we present a research whose approach is qualitative in the form of a case study about the Federal University of Ouro Preto / UFOP, in the state of Minas Gerais, Brazil. The data were collected from the application of a questionnaire with open questions about the three concepts and their articulation with the practice. On the basis of a part of the research data we find results that show that the managers have a greater knowledge on the theme of Inclusion, which does not extend to the other two concepts and identify some university actions that are also more focused on the inclusion field, particularly the disabled person.

KEYWORDS: Higher education. Inclusion. Interculturality. Pedagogical innovation.

\section{Introdução}

A UFOP está localizada na Região Sudeste, em Minas Gerais, Brasil e foi criada em 21 de agosto de 1969, pelo Decreto-Lei nº 778 , a partir com a fusão de duas escolas isoladas, a Escola de Farmácia, fundada em 1839, e a Escola de Minas e Metalurgia, de 1876. No momento da pesquisa contava com três campi, 11 unidades acadêmicas, 52 cursos de graduação, 68 cursos de pós-graduação, cerca de 13 mil e 400 alunos regularmente matriculados, 863 professores e 775 técnicos administrativos em educação ${ }^{4}$.

Desde 1990, a Instituição busca garantir a implantação de uma Política de Educação Inclusiva, para as pessoas com deficiência, desenvolvendo ações por meio do Núcleo de Educação Inclusiva. No ano de 2016, a UFOP passou a fazer parte do Observatório Internacional de Inclusão, Interculturalidade e Inovação Pedagógica

${ }^{4}$ As informações foram obtidas no Sistema de Controle Acadêmico da UFOP em 14 de setembro de 2014. 
(OIIIIPe), o que contribuiu para fortalecer nosso compromisso com os estudos na temática e potencializar a investigação no interior da nossa Instituição, a fim de contribuir para reflexões futuras e efetivação de ações descolonizadoras.

Em 2017, a partir do trabalho cooperativo entre as universidades participantes do OIIIIPe, buscamos evidenciar como os gestores da UFOP, concebem Inclusão, Interculturalidade e Inovação Pedagógica. Por meio da aplicação de questionário realizamos a coleta de dados nos diferentes níveis de gestão universitária. Como Santos (2003), partimos do princípio de que todos são responsáveis pela vida da instituição e qualquer desafio nela ocorrido é de responsabilidade de todos e não de apenas uma pessoa ou um segmento da comunidade escolar. A pesquisa surgiu, portanto, de nossas experiências vinculadas a desafios de nossa atuação profissional na UFOP e dos conhecimentos construídos, em rede, no OIIIIPe.

Estudos realizados, por Reis (2010) e por Silva (2016), trazem dados importantes acerca das políticas, vivências e conhecimentos de estudantes com deficiência em processo de inclusão na UFOP. Os dados das pesquisas indicam que haviam uma pré-disposição dos docentes, dos técnicos e dos estudantes da UFOP para a efetivação de práticas inovadoras e inclusivas, com vistas ao respeito às diferenças. Por outro lado, tais práticas ocorriam mais como ações isoladas, do que como política institucional. Muitas outras demandas eram silenciadas, fortalecendo focos de exclusão. Cabe destacar que não identificamos estudos que revelavam o que os gestores da UFOP pensavam acerca da proposição de uma universidade intercultural, inovadora e inclusiva.

Nessa perspectiva, este artigo, tem o propósito de apresentar estudo que investigou como os pelos gestores da UFOP concebem os conceitos inclusão, interculturalidade e inovação pedagógica. Para tanto, o texto está dividido em três partes. Na primeira, é apresentado um panorama acerca dos conceitos em estudo. $\mathrm{Na}$ segunda, os procedimentos metodológicos da investigação. Na terceira, apresentação e análise dos dados coletados a partir da pesquisa.

\section{Inclusão: entrada, permanência e formação}

$\mathrm{O}$ acesso irrestrito à educação escolar foi marginalizado pelo sistema educacional na maioria dos países do mundo até meados do século XX (MAZZOTTA, 2005, p. 15). A educação era então destinada a alguns indivíduos eleitos, considerados 
merecedores do direito de percorrer os segmentos da escolarização, muito embora essa condição ainda esteja presente nos dias de hoje em algumas práticas dos sistemas brasileiros (PARO, 2001; MANTOAN, 2006). Assim, é de conhecimento o histórico da permanência de uma ideologia de exclusão de sujeitos quanto à sua identidade étnica, de gênero, orientação sexual, geracional, religiosa, de classe, se fazem muito presentes no âmbito educacional. Daí infere-se que há algumas décadas, ao abrir a porta da escola pública brasileira para toda a sociedade, não tem sido garantido, na mesma medida à população, incondicionalmente, um percurso escolar confortável, adequado e de qualidade (PARO, 2001).

Em função dessas e outras questões, o atendimento à diversidade e ao público alvo da educação especial vem passando por mudanças importantes no campo jurídico e político nas últimas três décadas. Um marco dessas mudanças é a Declaração de Salamanca que, em 1994 estabelece mecanismos legais reafirmando o pacto com o projeto de uma educação para todos. É fato que as leis, por si só, não operam transformações. Nesse caso, é premente a necessidade de implementação de políticas públicas que, orientadas por documentos governamentais tais como, no caso do Brasil, as Diretrizes Curriculares Nacionais - DCNs/05, os Parâmetros Curriculares Nacionais PCNs/97 e 98, as Diretrizes Nacionais para a Educação Especial na Educação Básica/01, permeiem todo o sistema educacional do país no intuito de possibilitar uma educação de qualidade diante da diversidade (LAPLANE, 2007).

No entanto, ainda que as políticas governamentais e documentos oficiais estejam caminhando numa direção para que todos, sem exceção, tenham acesso à e permanência na escola, desfrutando de uma educação de qualidade, nada disso adiantará, caso os responsáveis por isso, professores e comunidade, não tenham clara uma concepção de inclusão que, segundo Ainscow (2009), envolve:

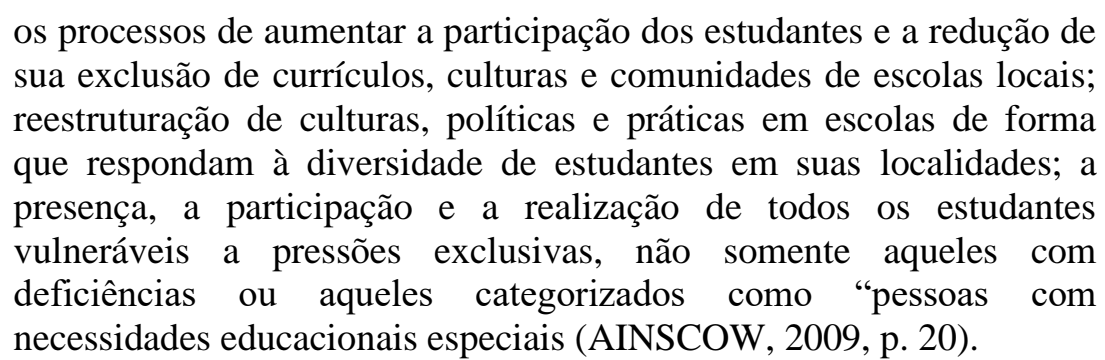

Sem essa compreensão alargada do que vem a ser inclusão, corremos o risco de manter o paradigma da integração cujo olhar se fixa naquilo que deve ser mudado e não no respeito às diferenças. Dessa forma, embora o estudante tenha acesso, a sua 
permanência na escola estará comprometida, uma vez que terá que se submeter a um processo de normalização, cujo objetivo final é enquadradá-lo em um modelo de educação que ignora suas diferenças. Não se percebe ações efetivas para sua permanência.

A permanência do estudante na escola se dá na concretização do processo de aprendizagem, no fornecimento de uma educação de qualidade e no respeito e valorização das diferenças. Essa consolidação acontece quando o trabalho desenvolvido pelos professores parte das necessidades desses discentes, já que o processo de ensino só é eficaz se houver o processo de aprendizagem e, para que esse último aconteça, é preciso enfatizar suas especificidades, fazendo com que esses sujeitos sejam compreendidos de forma integral e singular.

Ao se pensar em uma pedagogia para a diversidade, uma das políticas em questão diz respeito à qualificação do profissional docente, sendo importante ressaltar que este se constitui em um dos mecanismos capazes de precarizar ou edificar práticas educacionais inclusivas. Atualmente, o currículo para a formação de professores no ensino superior deve contemplar disciplinas e temas que, ampliem os sentidos da educação escolar para debates em torno de questões nas quais está situada a diversidade humana, que embora possam estar incorporadas nos alunos que frequentam a escola, estes podem não encontrar necessariamente uma representação positiva de suas identidades e necessidades nesse espaço (PIETRO, 2006).

O professor que, em sua formação, teve a oportunidade de se apropriar de uma concepção de inclusão de forma não reducionista e que respeita as diferenças, ao invés de ignorá-la, estará apto a "romper com as barreiras atitudinais de preconceito, estigmas e indiferença em torno do estudante com deficiência" (TORISU; SILVA, 2016, p. 274) e todos aqueles que, de alguma forma, são excluídos por barreiras que são criadas e fortalecidas socialmente.

\section{Interculturalidade}

A história da humanidade ilustra a recusa, a intolerância, o desprezo diante de determinados grupos humanos considerados “"estranhos". Fazer parte de um grupo, implica o não pertencimento a outro, "e por outra parte, o grupo de todos sem exclusões, tem sido sempre uma abstração ideal impossível” (FRIDMAN, 2017, p. 87). O que não significa que como humanos, não lutemos por horizontes de convivência 
respeitosa e processos interativos significativos. Aceitar o outro e acolhe-lo com respeito significa inseri-lo nos vínculos sociais. Tolerar e suportar a presença daqueles classificados como diferentes seja por questões de etnia, de religião, de culturas e em situação de deficiência, não significa acolhe-los. São atitudes distintas e consequentemente, provocam diferentes reações, demandando a criação de espaços de interação na sociedade para superar os estigmas negativos em relação às diferenças. Trata-se de possibilitar o diálogo, para potencializar a ação desencadeada pelos conflitos. Muitas vezes esses conflitos são silenciados, contribuindo para novas formas de exclusão.

Ao ressaltarmos os aspectos históricos, sabemos que as formas prevalecentes de tratar os considerados diferentes, em espaços públicos e políticos, foram formas de exclusão: abandono, segregação, discriminação e marginalização, e por mais que julguemos tais atitudes como retrógradas e ultrapassadas, estas como formas de "tratamento", continuam a pairar sobre o imaginário sócio-político atual. Considerar que formas absurdas de exclusão ainda insistam em se fazer presentes nos impõe a trazer o assunto para o debate intelectual considerando os conflitos ideológicos.

Abordar a categoria da Interculturalidade como uma bandeira de luta enriquece o debate uma vez que traz em seu escopo a necessidade de discutir o tema com a população como um todo, não sendo um assunto exclusivo para aqueles vitimas de processos discriminatórios e segregacionistas. Ou seja, não significa um assunto restrito aos grupos minoritários. Trata-se de abrir os olhos ao estranhamento, deslocar do conhecido para o desconhecido, que não é só o outro sujeito com quem interagimos socialmente, mas também o outro que habita em nós mesmos.

Para Romero (2010), foi a partir de 1987 que o termo Interculturalidade surge em substituição ao paradigma do multiculturalismo. Para o autor, o termo é valorativo e normativo, não significando apenas uma troca de termos. Se o multiculturalismo ressaltava a coexistência de diversos grupos humanos em posição de igualdade e reconhecimento de direitos, a Interculturalidade além de valorizar a diversidade humana afirma a necessidade de convivência em posição de diálogo e negociação. Essa compreensão rompe com uma visão de educação que pressupõe práticas baseada em estereótipos.

A solidariedade e o acolhimento se fazem necessários, no combate às manifestações de preconceitos e conflitos de ordem econômica, social e educacional presentes nos contextos institucionais existentes. É neste contexto que o termo 
Interculturalidade surge, buscando enfatizar a necessidade de negociação, diálogo e convivência que valorize o respeito, e não desconsidere as diferenças entre os diversos agrupamentos humanos, podendo ser definida como

[...] complexo campo de debate entre as variadas concepções e propostas que enfrentam a questão da relação entre processos identitários socioculturais diferentes focalizando especificamente a possibilidade de respeitar as diferenças e de integra-las em uma unidade que nào as anule. A interculturalidade vem se configurando como uma nova perspectiva epistemológica, ao mesmo tempo é um objeto de estudo interdisciplinar e transversal, no sentido de tematizar e teorizar a complexidade(para além da pluralidade ou da diversidade) e a ambivalência ou hibridismo( para além da reciprocidade ou da evolução linear ) dos processos de elaboração de significados nas relações intergrupais e intersubjetivas, constituídas de campo identitários em termos de etnias, de gerações, de gênero, de ação social (FLEURI, 2003, p. 17).

Nos países da América Latina a dizimação de populações indígenas, o preconceito e racismo com a população afrodescendentes, a segregação de grupos minoritários têm provocado tensões e trazido o debate para o cenário social e intelectual em busca da construção de políticas públicas que atendam as reinvindicações e o reconhecimento das injustiças e discriminações sofridas.

Os desafios impostos hoje aos estados modernos regidos por sistemas democráticos que se distanciam dos interesses da maioria da população ameaçam a existência e a permanência de politicas públicas fundamentadas em princípios da Interculturalidade para a gestão da diversidade sociocultural, pois como salienta Romero (2010, p. 29) "de nada vale afirmar a perspectiva intercultural se se mantiverem a discriminação, a segregação ou outras práticas".

Dentro desta perspectiva, as instituições escolares, desde os níveis mais básicos, se destacam como espaços ricos em diversidade humana, desde que adotem como ponto de partida a rejeição da exclusão e o reconhecimento das diferenças, o que implica diálogo, se colocar no lugar do outro. (ROMERO, 2010; CANDAU, 2012; OLIVEIRA, 2015).

Entretanto, para que as escolas, sobretudo as universidades, se transformem em instituições promotoras de uma educação fundamentada na interculturalidade, necessitam passar por processos transformadores em seus currículos e práticas educativas, promovendo novas atitudes baseadas no reconhecimento da urgência em discutir e valorizar diferenças entre os diversos grupos humanos. Há que considerar que 
as diferenças aparentemente negadas não desaparecem, mas se transformam em desigualdades sociais e em processos de marginalização.

Para Candau (2012) a construção de práticas socioeducativas referidas à interculturalidade,

exige colocar em questão as dinâmicas habituais dos processos educativos muitas vezes padronizados e uniformes desvinculados dos contextos socioculturais dos sujeitos que deles participam e baseadas no modelo formal de ensino-aprendizagem. Favorecem dinâmicas participativas, processos de diferenciação pedagógica e utilização de múltiplas linguagens e estimulam a construção coletiva (CANDAU, 2012, p. 246)

Nessa mesma direção Fleuri (2003) defende o desenvolvimento de processos de educação no interior de nossas universidades que não anule as diferenças humanas. A educação deve ser entendida como o processo construído pela relação tensa e intensa entre diferentes sujeitos. E cabe às universidades a criação de contextos interativos, tornando-se, um ambiente criativo e propriamente formativo. Portanto, em todos os movimentos sociais e educacionais, em âmbito nacional e internacional, que propõem a convivência democrática entre diferentes grupos e culturas, o trabalho intercultural pretende contribuir para superar tanto a atitude de medo quanto a de intolerância ante o "outro", construindo uma disponibilidade para a leitura positiva da diferença humana. $\mathrm{O}$ que configura uma proposta de "educação para a alteridade", aos direitos do outro, à igualdade de dignidade e de oportunidades.

\section{Inovação Pedagógica}

Quando nos referimos à inovação pedagógica é sempre importante diferenciá-la de inovação tecnológica. Os dois conceitos são comumente confundidos e, por vezes, transformados em similares ou equivalentes. Para Fino (2011), a inovação tecnológica não traz mudanças efetivas na escola. $\mathrm{O}$ simples fato de se ter um aparato tecnológico em qualquer instituição escolar não a credencia como uma instituição inovadora no campo pedagógico. Fino (2011, p. 2) entende a

Inovação pedagógica como ruptura de natureza cultural, se tivermos como fundo as culturas escolares tradicionais. E abertura para a emergência de culturas novas, provavelmente estranhas aos olhares conformados com a tradição. Para olhos assim, viciados pelas rotinas 
escolares tradicionais, é evidente que resulta complicado definir inovação pedagógica, e tornar a definição consensual. No entanto, o caminho da inovação raramente passa pelo consenso ou pelo senso comum, mas por saltos premeditados e absolutamente assumidos em direcção ao muitas vezes inesperado. Aliás, se a inovação não fosse heterodoxa, não era inovação.

O autor reforça que as inovações pedagógicas envolvem práticas e portanto, não devem ser procuradas nas reformas curriculares ou de ensino. Fino (2011) ressalta ainda que a inovação pedagógica não é algo que aconteça do externo para o interno. Ela resulta de um processo de reflexão, criatividade, critica e autocrítica.

Outra perspectiva de se compreender a inovação pedagógica nos é fornecida por Veiga (2003). A autora classifica a inovação em duas vertentes. A primeira ela chama de regulatória e a segunda nomeia de emancipatória. Na perspectiva regulatória a autora revela que o foco da inovação está na padronização e na racionalidade técnica. Nesse sentido, a inovação não passa de uma (re) produção do mesmo sistema. Ou seja ela produz o mesmo sistema modificado. Já a perspectiva emancipatória aponta para um processo contrário ao regulatório. Essa perspectiva pressupõe uma ruptura paradigmática, assim como também nos aponta Fino (2011). Além disso, busca superar a fragmentação das ciências e propõe o repensar das relações sociais e culturais.

Cunha (2008), acrescenta que a reconfiguração dos saberes é uma outra categoria importante a ser considerada ao abordarmos o tema da inovação pedagógica. Para a autora, compreender a reconfiguração dos saberes numa perspectiva de ruptura paradigmática significa romper, de alguma maneira, com a dualidade epistemológica posta pela ciência moderna. Nesta perspectiva, Cunha (2008, p. 25) diz que:

Se essa se sustentava na classificação e na dicotomização dos seres e dos saberes, o que se propõem como novo é o abandono das estratificações dualistas entre saber científico/saber popular, ciência/ cultura, educação/trabalho, corpo/alma, teoria/prática, ciências naturais/ciências sociais, objetividade/subjetividade, arte/ciência, ensino/pesquisa e tantas outras formas propostas para a compreensão dos fenômenos humanos.

Com isso, a autora reforça a importância de se compreender e considerar a inovação pedagógica como integradora da totalidade e legitimadora dos diferentes saberes e de suas articulações. Vai além ao dizer que é necessário também se repensar a relação teoria e prática, a qual "no sentido de ruptura, a reorganização dessa relação assume que a dúvida epistemológica é que dá sentido à teoria” (CUNHA, 2008). 


\section{Processo metodológico da investigação}

$\mathrm{Na}$ tentativa de compreender como os gestores da UFOP concebem interculturalidade, inovação pedagógica e inclusão, foi desenvolvido um estudo qualitativo o qual segundo Lüdke e André (2012), tem o ambiente original como fonte de coleta de dados, e o pesquisador como seu principal instrumento. Esse tipo de abordagem centra sua análise mais sobre os processos do que sobre os produtos da investigação, sendo os dados coletados, predominantemente, descritivos. Para tanto, empregou-se a metodologia do estudo de caso que permite interrogar e descrever as situações específicas do objeto investigado. Segundo Yin (2001) o estudo de caso é caracterizado por aprofundar a observação e descrição de um determinado fenômeno, em seu contexto real.

Foi utilizado um questionário com questões abertas a serem respondidas por gestores da UFOP. Para a construção do instrumento de coleta de dados levou-se em conta critérios fundamentais para a elaboração de perguntas em pesquisas qualitativas, como: consideração dos objetivos da pesquisa; amplitude da questão para permitir o desvelamento de informações pertinentes ao tema da pesquisa; cuidado para evitar indução de respostas (SZYMANSKI, 2011).

Elaborou-se, assim, o questionário com perguntas norteadoras, que tinham como objetivo trazer à tona as concepções dos gestores acerca dos conceitos de inclusão, interculturalidade e inovação pedagógica e identificar dispositivos colonizadores nas relações que permeiam o cotidiano da UFOP.

O questionário foi enviado a 120 gestores da UFOP, no mês de maio de 2017. A relação dos sujeitos da pesquisa e seus endereços eletrônicos foram disponibilizados pelo setor de Registro Acadêmico da Pró-Reitoria de Graduação da UFOP. Além do questionário, o arquivo enviado continha uma Carta de Apresentação do estudo e o Termo de Consentimento Livre e Esclarecido (TCLE).

Dos 120 questionários enviados, obtivemos 30\% de respostas. Assim, a amostra, em conformidade com os objetivos do estudo, foi composta por 36 gestores, sendo próreitores, coordenadores de cursos de graduação (bacharelados e licenciaturas), chefe de departamentos e diretores de unidades acadêmicas.

\section{Intercuturalidade, Inovação Pedagógica, Inclusão e a Universidade}


Nesta seção nos propomos a discutir algumas respostas apresentadas pelos gestores da UFOP relacionadas à compreensão dos conceitos de Interculturalidade, Inclusão e Inovação Pedagógica, além de exemplos da aplicação desses conceitos na instituição acadêmica. Iniciamos, apresentando algumas respostas no campo da inclusão:

"Promover a Educação como um direito social, oportunizando a todos a inserção, levando-se em conta suas limitações e suas diferenças."

Que todas as pessoas tenham acesso, independente do sexo, deficiência ou qualquer outra dificuldade que ela tenha.

"A possibilidade de participação de todas as pessoas em processos de educação, sejam eles formais (cursos formais como graduação, pós graduação) ou não."

"Atitude reflexiva em relação às práticas culturais com o objetivo de quebrar paradigmas e elaborar uma política educational que permita uma participação efetiva a qualquer indivíduo."

"Possibilidade de todos terem acesso à educação escolarizada."

Embora não possamos afirmar que sejam quantitativamente representativas do total de respostas, pois correspondem a cerca de $15 \%$ total, elas podem ser analisadas sob outro prisma. Há algo que as aproxima. Essa aproximação se dá em função de algumas palavras semelhantes ou sinônimos que são: inserção, participação, acesso.

As respostas apresentadas acima, com exceção da quarta, apresentam alguns aspectos que as aproximam e que refletem uma tendência nas muitas outras respostas coletadas. Podemos identificar que as palavras inserção, participação e acesso aparecem com mais frequência. $\mathrm{O}$ que nos chama a atenção é que a perspectiva de acesso e de oportunizar o acesso daqueles que são excluídos de determinados espaços sociais, no caso o escolar/universitário, é o que aparece com maior ênfase. Embora em algumas dessas respostas a palavra participação apareça, é possível notar que está, de alguma maneira, vinculada à perspectiva do acesso ou da inserção. Esse dado é importante para refletirmos que a ideia de oportunizar ainda se mantém vivo e presente no imaginário social mesmo com todo movimento e desenvolvimento de políticas que se tem feito no campo da inclusão em educação.

Considerando a noção de acesso é importante ressaltar conforme Mazzotta (2005) que a inserção das minorias nos espaços escolares é fundamental, mas não somete ela. $\mathrm{O}$ direito de acesso é garantido pela constituição brasileira, porém deve-se 
questionar se somente esse acesso seria a garantia de um processo inclusivo. Vale lembrar que para chegar ao ensino superior apenas o acesso não seria o responsável. A garantia de permanência é fundamental e deve ser de relevante consideração.

Se atrelarmos o conceito de inclusão ao acesso estaremos cometendo um grande equívoco e com certeza, contribuindo enormemente para o processo de exclusão. Como dissemos anteriormente, mesmo quando na resposta aparece a palavra participação, é possível identificar que essa participação está relacionada ao acesso. A resposta diz da possibilidade de participação nos processos e não de uma sociedade que respeite as diferenças e que todos participem sem qualquer tipo de discriminação. Essas respostas, que representam muitas outras, nos indicam o que podemos chamar de mais do mesmo, oportunizando o acesso dos sujeitos e mantendo a meritocracia como base do processo de inclusão em educação.

Em relação ao conceito de interculturalidade, a partir das respostas dos mesmos gestores temos:

\footnotetext{
"A possibilidade de apresentar nos processos de educação diferentes culturas e diferentes visões de mundo."

"Respeito à diversidade de sujeitos e conhecimentos."

"Desafio de oportunizar o conhecimento de diferentes culturas no ambiente educacional. A globalização, as migrações, a afirmação das minorias geram a necessidade de uma constante discussão que resulte no diálogo."
}

"Importante, pois expande as conexões cerebrais e abre mais a cabeça do educando e do educador à medida que ele prepara as aulas."

"Possibilidade de trabalhar com multiculturalismo."

Se tomarmos o conceito de Fleuri (2003) sobre interculturalidade veremos que o autor nos diz que interculturalidade pode ser compreendida como um campo complexo que envolve tensões no que diz respeito aos processos identitários socioculturais diferentes com o foco voltado para as diferenças e a sua integração, sem contudo anular essas diferenças. Temos então que a interculturalidade pressupõe ir muito além do multiculturalismo, da oportunidade de apresentar nos processos educacionais as diferenças. Trata-se de uma perspectiva de vida e de atuação como sujeito. De uma epistemologia e de um objeto de estudo (FLEURI, 2003). Seria, de nossa parte, um reducionismo enorme tratar o conceito como sendo algo do campo da participação e da oportunização como identificamos nas respostas acima. 
Já no campo da Inovação pedagógica, é possível observar o seguinte:

"Trazer para o processo de ensino e aprendizado elementos diferentes daqueles já existentes, como novos processos, novas metodologias, ou ainda elementos já existentes mas usados de forma diferente, como por exemplo o uso de música para o ensino de ciências exatas."

"Desenvolvimento e uso de Práticas e recursos, por parte dos docentes, que contribuam para o atingimento de seus objetivos pedagógicos."

"Busca constante por práticas diferenciadas de abordagens dos assuntos educacionais clássicos."

"Muito importante, pois as metodologias ativas melhoram as habilidades e competencias dos educandos, mas é preciso capacitor os professores, ainda há muita resistência."

"Promover a criação de novos processos pedagógicos procurando subjetivar os sujeitos na busca de torná-los mais independents e proativos."

De acordo com Fino (2011) a inovação pedagógica passa por uma ruptura paradigmática com o modelo de racionalidade técnica. $\mathrm{O}$ autor nos diz que o modelo atual de Educação escolar, em muito, não atende às necessidades e demandas da sociedade contemporânea. Quando relacionamos essa perspectiva do autor às respostas dos gestores, é possível identificar que nas falas apresentadas, a perspectiva de racionalidade técnica ainda se faz muito presente.

Geralmente, este conceito se confunde em muito com o conceito de Inovação tecnológica. Fino (2011) nos diz que são conceitos completamente diferentes e que a inovação tecnológica, não se configure em uma inovação pedagógica. Podemos entender então, que a mudança na forma de trabalho em sala de aula, não é por si só uma inovação pedagógica. Ela assim será quando evidenciar uma ruptura com modelos tradicionalmente adotados nos processos educacionais escolares.

As respostas acima, assim como a de muitos outros gestores se concentram fortemente no campo regulatório como nos indica Veiga (2003). A perspectiva que se evidencia nas falas salienta a eaboração de práticas diferentes, porem, podemos entender que essas práticas mantém na sua essencia o modelo de racionalidade técnica e não propõem uma ruptura com o modelo vigente.

Após discutirmos as respostas sobre os conceitos de inclusão, interculturalidade e inovação pedagógica, apresentamos no quadro a seguir, os exemplos de aplicação prática, na universidade, na visão dos mesmos gestores. Trata-se de outra pergunta feita 
a eles como forma de identificarmos como relacionam os conceitos e a sua materialização no cotidiano da universidade.

Quadro1 - Exemplos dos gestores sobre Inclusão, Interculturalidade e Inovação Pedagógica

\begin{tabular}{|c|c|c|c|}
\hline Gestores & Inclusão & Interculturalidade & $\begin{array}{l}\text { Inovação } \\
\text { Pedagógica } \\
\end{array}$ \\
\hline Gestor 1 & $\begin{array}{l}\text { Os programas de assistência } \\
\text { estudantil e as iniciativas de } \\
\text { extensão }\end{array}$ & Summer Programme 2016 & \begin{tabular}{l}
\multicolumn{2}{c}{ Metodologia } \\
por Projetos; Sala \\
Aberta; Moodle
\end{tabular} \\
\hline Gestor 2 & $\begin{array}{l}\text { Práticas de assistência } \\
\text { estudantil. } \\
\text { prestada pelo núcleo de } \\
\text { Educação Inclusiva }\end{array}$ & $\begin{array}{l}\text { Desconheço algo formal } \\
\text { para além do NEABI } \\
\text { (Núcleo de estudos Afro } \\
\text { Brasileiros e Indígenas) }\end{array}$ & $\begin{array}{l}\text { Sala aberta e Pró- } \\
\text { ativa }\end{array}$ \\
\hline Gestor 3 & $\begin{array}{l}\text { O Núcleo de } \text { Educação } \\
\text { Inclusiva - NEI - realiza } \\
\text { várias ações e uma delas foi } \\
\text { apresentada durante o } \\
\text { SIMPOED e tratava da } \\
\text { confecção de material } \\
\text { pedagógico para deficientes } \\
\text { visuais. A própria criação de } \\
\text { oportunidades } \\
\text { permanência dos alunos na } \\
\text { cidade de Ouro Preto pode } \\
\text { ser considerada uma prática } \\
\text { de inclusão por meio das } \\
\text { diversas bolsas. }\end{array}$ & $\begin{array}{l}\text { O PIBID realiza diversas } \\
\text { atividades, há inclusive o } \\
\text { subprojeto PIBID-AFRO } \\
\text { que trabalha com a } \\
\text { valorização da cultura afro } \\
\text { não apenas em ações na } \\
\text { UFOP, como também nas } \\
\text { escolas estaduais e } \\
\text { municipais de Ouro Preto } \\
\text { e Mariana }\end{array}$ & $\begin{array}{lr}\text { Desenvolvidas } & \text { por } \\
\text { iniciativas pessoais de } \\
\text { professores de forma } \\
\text { assistemática e não } \\
\text { documentada } \\
\text { instituição. }\end{array}$ \\
\hline Gestor 4 & $\begin{array}{l}\text { Rádio, computador, leitura } \\
\text { auditiva ou relevo, filmes, } \\
\text { roda de conversas, oficinas } \\
\text { de jogos, visitas técnicas em } \\
\text { empresas, } \\
\text { assistida observação }\end{array}$ & $\begin{array}{l}\text { Visitas a museus, } \\
\text { orquestras, oficinas iversas } \\
\text { e construção de materiais, } \\
\text { aproveitamento integral de } \\
\text { alimentos, oficinas com } \\
\text { caixas que são } \\
\text { descartáveis ou mesmo } \\
\text { com papéis } \\
\text { descartados.Teatro, } \\
\text { música, brincadeiras... }\end{array}$ & $\begin{array}{l}\text { A utilização da } \\
\text { plataforma moodle } \\
\text { mesmo pelos cursos } \\
\text { presenciais. } \\
\text { disponibilizaçào da } \\
\text { rede Minha UFOP } \\
\text { WIFI que permite aos } \\
\text { professores levarem } \\
\text { atividades de busca } \\
\text { que os alunos têm } \\
\text { condiçòes de realizer } \\
\text { nos seus próprios } \\
\text { smartphones dentro } \\
\text { das salas de aula. }\end{array}$ \\
\hline Gestor 5 & $\begin{array}{l}\text { As Práticas promovidas pelo } \\
\text { NEI (Núcleo de Educação } \\
\text { Inclusiva). Aulas dos } \\
\text { conteúdos de Ciências } \\
\text { Humanas e Sociais. }\end{array}$ & $\begin{array}{l}\text { As Práticas promovidas } \\
\text { pelo NEI (Núcleo de } \\
\text { Educação } \\
\text { Aulas dos } \\
\text { Anclusiva). } \\
\text { Ciências Humandos de } \\
\text { Sociais. } \\
\text { Sumas e }\end{array}$ & $\begin{array}{l}\text { Proposição de } \\
\text { metodologias diversas } \\
\text { que visem tornar o } \\
\text { aluno protagonista do } \\
\text { próprio } \\
\text { conhecimento: jogos }\end{array}$ \\
\hline
\end{tabular}




\begin{tabular}{|l|l|l|l|}
\hline & & $\begin{array}{l}\text { educativos, aulas } \\
\text { Práticas, etc. }\end{array}$ \\
\hline
\end{tabular}

Fonte: ?

A partir do quadro acima podemos observar que os exemplos dos gestores em muito têm a ver com as concepções sobre os três conceitos a que eles responderam. Em relação inclusão é possível observar que as respostas apontam para a execução de práticas assistencialistas. Evidenciam a preocupação com um programa que possa assistir ao aluno e não com ações de fato inclusivas que considere a diferença como algo inerente a todo e qualquer sujeito.

Quanto aos exemplos de interculturalidade identificamos um certo desconhecimento de sua representação no campo da prática e a indicação de programas e projetos desenvolvidos na universidade que se configuram a partir de políticas públicas do governo brasileiro. Identificamos também ações práticas que tratam muito mais de aspectos didático-pedagógicos do que interculturais.

No campo da inovação pedagógica, os exemplos revelam perspectivas muito voltadas para os aspectos tecnológicos. Novamente, observamos a confusão entre os conceitos de inovação pedagógica e de inovação tecnológica. Além disso, uma das falas indica como inovação o uso de metodologias que visem o protagonismo do aluno. É importante ressaltar que o protagonismo do aluno é de fundamental importância na construção de seu próprio conhecimento. Porém, isso, por si só, não pode se configurar em uma ação de caráter inovador pedagógico.

\section{Considerações finais}

A partir do recorte que fizemos foi possível refletir sobre a necessidade de se aprofundar os estudos sobre os conceitos de Interculturalidade, de Inovação pedagógica e de Inclusão no âmbito da universidade. Embora a amostra aqui apresentada seja pequena, os dados obtidos na coleta de dados, dão indícios de que os gestores educacionais necedssitam se aproopriar de informações relacionadas aos valores que podem estar associados às suas práticas quanto aos conceitos de Inclusão, Interculturalidade e Inovação pedagógica. Em relação à totalidade das respostas, ela nos é suficiente para levantarmos um sinal de alerta em relação ao pouco domínio conceitual dos gestores sobre os conceitos e também a ausência de uma proposta institucional. 
O movimento de transformação das culturas universitária, em culturas orientada pelos princípios da inclusão, da interculturalidade e da inovação pedagógica demanda envolver todos os segmentos da instituição, na responsabilização em identificar e remover barreiras e práticas colonizadoras. Isso nos remete a refletir sobre a compreensão desses conceitos no âmbito de toda a universidade.

Consideramos que nesse processo de construção de uma postura intercultural, inovadora e inclusiva, que exige a transformação da consciência individual e coletiva, a UFOP está des-cobrindo o caminho. Os desafios são grandes. Acreditamos que se torne necessário uma investigação mais minuciosa, abrangendo outras camadas acadêmicas para se mapear o que pensam os acadêmicos sobre tais conceitos e como os mesmos emergem em suas práticas acadêmicas cotidianas. Interessa-nos saber se/como os docentes da UFOP estão atentos para acolher o que o aluno os diz na sua alteridade; ou se atuam apenas com as representações de estudantes universitários abstraídas de padrões culturais genéricos e universalizantes, despidos de suas particularidades. A adoção de uma imagem universal e homogeneizante de estudante universitário pode ser responsável pela desconsideração das diferenças, o que dificulta o reconhecimento e a comunicação entre as culturas escolares e as culturas vividas.

\section{REFERÊNCIAS}

AMARO, D. G. Educação inclusiva, aprendizagem e cotidiano escolar. 1. ed. São Paulo: Casa do Psicólogo, 2006.

FINO, C. N. Investigação e inovação (em educação). In: FINO, C.; SOUSA, J. M. (Orgs), Pesquisar para mudar (a educação). Funchal: Universidade da Madeira. 2011, p. $29-48$.

CUNHA, M. I. Inovações Pedagógicas: o desafio da reconfiguração de saberes na docência universitária. São Paulo: EdUSP, 2008. Caderno 6, Coleção Cadernos de Pedagogia Universitária.

FLEURI, R. Intercultura e educação. Revista Grifos, 5, p. 16-47, 2003.

FRIDMAN, P. La segregación y sus destinos. In: DELGADO, O.; FRIDMAN, P. Indagaciones psicoanalíticas sobre la segregación. Olivos: Grama Ediciones, 2017, p. 87-114.

GENOVESE, A.; VIEIRA, I. Interculturalidade e reflexão pedagógica em contexto de mudança social. Entrevista a Antonio Genovese, Forum Sociológico. Disponível em: http://journals.openedition.org/sociologico/1373. Acesso em: 10 jan. 2018. 
MATOS, S. N.; MENDES, E. G. A proposta de inclusão escolar no contexto nacional de implementação das políticas educacionais. Praxis Educacional, v. 10, n. 16, 2014 , p. 35-59.

FRANCO, M. A. R. S. Prática pedagógica e docência: um olhar a partir da epistemologia do conceito. Revista Brasileira de Estudos Pedagógicos, v. 97, n. 247, p. 534-551, 2016.

LAPLANE, A. L. F. Notas para uma análise dos discursos sobre inclusão escolar. In: GOÉS, M. C. R.; LAPLANE, A. L. F. (orgs.). Políticas e práticas de educação inclusiva. São Paulo: Autores Associados, 2007, p. 5-20.

MANTOAN, M. T. E. Igualdade e diferenças na escola: como andar no fio da navalha. In: ARANTES, V. A. (org). Inclusão: pontos e contrapontos. São Paulo: Summus, 2006.

MAZZOTA, M. J. S. Educação especial no Brasil: História e políticas públicas. 5. ed. São Paulo: Cortez, 2005.

OLIVEIRA, G. A. Interculturalidade: errâncias do imaginário. Porto: Universidade do Porto, Faculdade de Letras, 2015.

PARO, V. H. Escritos sobre Educação. São Paulo: Xamã, 2001.

PIETRO, R. G. Formação de profissionais da educação para trabalhar com o atendimento de alunos com necessidades educacionais especiais no sistema regular de ensino. In: ARANTES, V. A. (org). Inclusão: pontos e contrapontos. São Paulo: Summus, 2006.

REIS, N. M. de M. Política de inclusão escolar de pessoas com necessidades educacionais especiais no Ensino Superior e as Universidades Federais Mineiras. Dissertação (Mestrado em Educação) - Programa de Pós-graduação em Conhecimento e Inclusão Social, Faculdade de Educação, Universidade Federal de Minas Gerais, Belo Horizonte, 2010.

ROMERO, C. Interculturalidade e mediação. Caderno de Apoio à Formação. Lisboa: Alto Comissariado para a Imigração e Diálogo Intercultural, 2010.

SILVA, M. M. Processo de inclusão no ensino superior: o caso de estudantes com deficiência na Universidade Federal de Ouro Preto. Dissertação (Mestrado em Educação) - Programa de Pós-graduação em Educação, Universidade Federal de Ouro Preto, Ouro Preto, Minas Gerais, Brasil, 2016.

SZYMANSKI, H.; ALMEIDA, L. R.; PRANDINI, R. C. A. R (orgs.). A entrevista na pesquisa em educação: a prática reflexiva. Brasília: Liber Livro, 2011.

VEIGA, I. P. A. Inovações e projeto político-pedagógico: uma relação regulatória ou emancipatória? Caderno Cedes, v. 23, n. 61, p. 267-281, 2003. 
YIN, R. K. Estudo de caso: planejamento e métodos. Porto Alegre: editora: Bookmam, 2001.

\section{Como referenciar este artigo}

FRANCO, M. A. M.; SILVA, M. M. da.; TORISU, E. M. Inclusão, interculturalidade e inovação pedagógica no contexto Ensino Superior: o que dizem os gestores. Revista on line de Política e Gestão Educacional, Araraquara, v. 23, n. esp. 1, p. 698-715, out. 2019. E-ISSN:1519-9029. DOI: https://doi.org/10.22633/rpge.v23iesp.1.13020

Submetido em: 10/05/2019

Revisões requeridas: 14/06/2019

Aprovado em: 10/08/2019

Publicado em: 01/10/2019 